\title{
Sürdürülebilir Destinasyon Yönetimi İçin Bir Model Önerisi: Ayvalık Örneği ${ }^{1}$
}

DOI: 10.26466/opus.896321

\author{
* \\ Yakup Dinç*- Taner Kömür ${ }^{* *}$ - Mehmet Oğuzhan İlban*** \\ * Dr. Öğretim Üyesi, Balıkesir Üniversitesi, Ayvalık Meslek Yüksekokulu, Balıkesir/Türkiye \\ E-Posta: yakdin@yahoo.com \\ ORCID: 0000-0002-6533-3987 \\ ** Bilim Uzmanı, Balıkesir Üniversitesi, Sosyal Bilimler Enstitüsü, Balıkesir/Türkiye \\ E-Posta: tanerkomur@hotmail.com \\ ORCID: 0000-0001-8348-540X \\ *** Prof Dr., Balıkesir Üniversitesi, Burhaniye Uygulamalı Bilimler Yüksekokulu, Balıkesir/Türkiye \\ E-Posta: İlban@balikesir.edu.tr \\ ORCID: $\underline{0000-0002-7557-9817}$
}

Öz

Destinasyonların rekabet avantajı elde etmek için doğal, kültürel kaynaklarım kontrollü biçimde kullanarak koruması ve sürdürülebilir turizm konusuna önem vermeleri gerekmektedir. Bu noktada; destinasyon yönetimini oluşturan paydaşların ürün geliştirme, ziyaretçi yönetimi, destinasyon pazarlaması, ortak rekabet gücü yaratma, lobicilik, piyasa düzenlemesi, kriz yönetimi, finansal kaynak bulma gibi sürdürülebilir destinasyonun yaratılmasında gerekli işlevleri yerine getirmesi ve ortak kararlar alabilmesi için örgütlenme çok önemlidir.

Araştırmanın amacl; turizm ve zeytin kenti olan Ayvalık'ın daha sürdürülebilir bir destinasyon olmasını sağlayacak öneriler geliştirmek, bunun için yapılması gerekenleri paydaşlara iletebilmek ve Ayvalık'ın sürdürülebilir destinasyon olarak yönetilebilmesi amactyla paydaşlar için bir model geliştirmektir. Bu çalışmada geliştirilen modelin, Ayvalık'ta uygulanması ve sonuçlarının hem Ayvalık hem de diğer destinasyonlar için yapılacak çalışmalara yardımo olması amaçlanmıştır. Araştırmada yarı yapılandırılmış görüşme tekniği uygulanmıştır. Veriler, katılımo görüşleri ve araştırmacının gözlemlerinden oluşmaktadır. Araştırma kapsamında merkezi yönetim, yerel yönetim, özel sektör, sivil toplum kuruluşları ve diğer (yerel halk, turistler, vs.) kategorileri altında toplam 42 paydaşla görüşülmüştür. Verilerin analizinde betimsel analiz ve içerik analizi teknikleri kullanılmıştır. Bulgular, gözlemler ve literatür taramasından yola çıkarak Ayvalık'ın sürdürülebilir destinasyon yönetimi için "Örgütlenme Modeli" ortaya konmuştur.

Anahtar Kelimeler: Sürdürülebilir Turizm, Sürdürülebilir Destinasyon Yönetimi, Destinasyon Yönetim Modeli, Ayvalık.

\footnotetext{
${ }^{1}$ Bu makale, Taner KÖMÜR'ün yüksek lisans tezinden hazırlanmıştır.
} 


\title{
A Model Proposal For Sustainable Destination Management: The Case Of Ayvalık
}

\begin{abstract}
Destinations need to conserve natural and cultural resources by using in a controlled manner and attach importance to sustainable tourism to be able to obtain competition advantage. At this point; organizing among the stakeholders consisting destination management is very important for shared decision making and carrying out necessary functions such as product development, visitor managemet, destination marketing, creating common competitive power, lobbying, market regulatory, crisis management and finding financial resource.

The purpose of research is to develop suggestions that provide Ayvalik, tourism and olive oil city, to become more sustainable destination, conveying of things to do to the stakeholders and develop a model to manage Ayvalik as a sustainable destination. The model developed in this study is aimed to apply in Ayvalik and help new researchs that will be implemented in Ayvalik and other destinations in future. In this research, semi-structured interview technique has been performed. Data consists of comments of participants and author's observations. Within research, forty two stakeholders under the categories of centralized administration, local administration, private sector, non-governmental organizations and other (local community, tourists, etc.) have been interviewed. Descriptive and content analyses have been performed in analysing of the data. "Organization Model" for sustainable destination management of Ayvalik has been put forward based on findings, observations and literature search.
\end{abstract}

Keywords: Sustainable Tourism, Sustainable Destination Management, Destination Management Model, Ayvalik. 


\section{Giriş}

Sürdürülebilirlik; çevre, büyüme ve kalkınma arasındaki ilişkilerde olumsuz etkilerin azaltılması ve toplumların işlerini bozulmadan, yaşamın ana kaynaklarını aşırı tüketmeden devam ettirebilmesi için gerekli dengeyi sağlamaktır (Demircan, 2016, s.19; Gündüz, 2016, s.104). Sürdürülebilir turizm; kültürel bütünlüğün, ekolojik süreçlerin, biyolojik çeşitliliğin ve yaşamın devamlılı̆̆ını sağlarken ekonomik, sosyal ile estetik ihtiyaçların karşılanması ve tüm kaynakların yönetimidir. Bu yaklaşım; gelecek planlamasının geliştirildiği, turistlerin ve yerel halkın ihtiyaçlarının karşılandığı bir turizm anlayışıdır (Gündüz, 2016, s.105; Uca, 2019, s.117).

Destinasyonlar; küresel trendlere uyum sağlamak ve rekabet avantajı için sürdürülebilir turizm ve sürdürülebilir destinasyon konularına önem vermelidir. Kaynaklarını yeterli değerlendiremeyen, yaratıcı pazarlama gerçekleştiremeyen ve sürdürülebilir gelişimi sağlayamayan destinasyonlar pazardaki konumların kaybederler (Yılmaz, 2014, s.279). Sürdürülebilir turizm; tüm paydaşların gelişimden faydalanmasıdır. Bu bakış açısı; destinasyon yönetim mantığının çok paydaşlı, ortak karar ve faaliyet gerçekleştirmeye öncelik veren yapısıyla benzerdir ve bütüncül yaklaşım için yapılacaklar belirlenmelidir (Türkay, 2014, s.234; Artun, 2016, s.138).

Uluslararası literatürde sürdürülebilir turizm ile ilgili çok sayıda yayın ve model olmasına karşın ülkemizde gerek kavramsal gerekse sektöre yönelik uygulamalar ile ilgili yeterli sayıda modele sahip olunmadığı görülmektedir. 2007 yılında yayınlanan 2023 Türkiye Turizm Stratejik Planında yerel, bölgesel ile ulusal konseylerin oluşturulması ve destinasyon yönetiminin bu konseyler tarafından yürütülerek turizmin geliştirilmesi planlanmıştır. Fakat bu ifadeye rağmen Türkiye' de az sayıda destinasyon yönetim konseyleri oluşturulmuştur (2023 Türkiye Turizm Stratejisi, 2007, s.45; Şanlıöz-Özgen, 2016, s.149; İlban, 2019, s.84).

Destinasyonların doğal ve kültürel özellikleri farklıdır ve her destinasyonun kendine özgü bir yönetim modeli geliştirmesi gerekmektedir (Özdemir, 2014, s.34). Destinasyonların turizme ürün çeşitliliği kazandırmaları için sürdürülebilir turizm çalışmaları yapmaları gerekmektedir. Bu sebeple günümüzde destinasyon yönetim örgütlerinin oluşturulması ve merkezi yönetimi rahatlatacak önerilerin geliştirilmesinin önemi artmıştır. Ayvalık destinasyonunun sürdürülebilirliğini sağlamak için doğal, tarihi ve kültürel kaynakları 
korunmalı, yerel halkın sürdürülebilir turizme katılımı ile bilinçlendirmesi sağlanmalıdır. Destinasyon bazında sürdürülebilir yönetim ve pazarlama yapılması gerekmektedir. Benzer şekilde Pearce (2016, s.47), Yeni Zelanda'da destinasyon fonksiyonlarının koordinasyonu için bütüncül yaklaşımın gerektiği sonucuna ulaşmıştır. Ali vd., (2018, s.182), Malezya'nın Port Dickson destinasyonunda turizm gelişim stratejisinin paydaşların istek ve beklentileriyle uyumlu geliştirilmesine paydaşların olumlu yaklaşım sergileyeceği sonucunu ortaya çıkarmıştır. Aynı şekilde Fyall ve Garrod (2019, s.168), turistlerle halkın ortak amaçlarda birleştirilmesi, teknolojinin hızlı büyümesi, rekabetçi destinasyon sürdürülebilirliği ve turist memnuniyeti için bilgi alışverişini destinasyon düzeyinde yönetmek gerektiği sonucunu elde etmiştir.

Ayvalık'ın kendine has "Destinasyon Yönetim Modeli" oluşturması bölgeye katkı sağlayacaktır. Bu noktadan hareketle araştırmanın amacı; mevcut durum analizi yapmak, turizm ve zeytin kenti olan Ayvalık'nn sürdürülebilir destinasyon olmasını sağlayacak turizme ivme kazandıracak öneriler geliştirerek bölgeye katkı sağlamak ve sürdürülebilir destinasyon yönetimi için bir örgütlenme modeli geliştirmektir. Bu modelin, Ayvalık'ta uygulanması ve sonuçlarının hem Ayvalık hem de diğer destinasyonlardaki çalışmalara yardımcı olması amaçlanmıştır.

\section{Yöntem}

Çalışmada, araştırma amacıyla okuyucuya betimsel ve gerçekçi bir çerçeve sunmak, bu konuda katılımcıların görüş ve deneyimlerini doğrudan aktarabilmek için nitel araştırma yöntemi kullanılmıştır (Yıldırım ve Şimşek, 2011, s.48).

\section{Araştırmanın Evren ve Örneklemi}

Araştırmanın evreni, Ayvalık'ta turizm faaliyetlerini etkileyen ve turizmden etkilenen paydaşlardır. Örneklemini ise görüşme yapılan merkezi ve yerel yönetim, sivil toplum kuruluşları, özel sektör, yerel halk ve turistler olmak üzere 42 turizm paydaşı oluşturmaktadır. Bu çalışmada erişilmesi kolay olan durum seçilerek hız ve kolaylık sağlanması için çok amaçlı örnekleme yöntemlerinden kolayda ulaşılabilir durum örneklemesi kullanılmıştır. 


\section{Veri Toplama Araç ve Teknikleri}

Nitel araştırma yöntemlerinden biri olan mülakat (görüşme), bir yönüyle yüz yüze anket yöntemine benzese de bu yöntemde alınan cevaba göre yeni sorularla daha derinlemesine bilgi edinilmesi mümkündür (İslamoğlu ve Alnıaçık, 2016, s.221). Araştırmacı, mülakat boyunca gözlem yaparak görüşülenlerin tutum, davranış, jest ve mimikleriyle açıklanmak istenen bilgi olup olmadığı konusunda ipuçlarına ulaşabilir. Böyle bir durumda araştırmacı, yeni ürettiği sorularla örtülmek istenen bilgiye ulaşabilir (İslamoğlu ve Alnıaçık, 2016, s.223). Bu çalışmada, katılımcılarla görüşmede farklı sorular sorabilmek ve böylelikle daha zengin verilere ulaşabilmek amacıyla yarı yapılandırılmış mülakat (görüşme) tekniğinden yararlanılmıştır. 42 kişiyle yüz yüze görüşmeler yapılmış, 4 açık uçlu sorunun cevapları izin alınarak ses kaydına alınmiştır.

Araştırmanın görüşme formu, "Ayvalık'1 daha sürdürülebilir bir destinasyon olmasını sağlayacak öneriler ve sürdürülebilir destinasyon yönetimi için bir model geliştirmek" ana temasından yola çıkılarak hazırlanmıştır. Genç (2013, s.109) çalışmasında kullandığı sorular, Ayvalık'a uyarlanarak değiştirilmiş ve mülakat soruları hazırlanmıştır. Bu sorularda destinasyon yönetim örgütünün (DYÖ) yapılanması ve yapması gereken çalışmalara yönelik paydaş görüşlerinin ortaya çıkarılması amaçlanmıştır. Bu amaç doğrultusunda, aşağıda yer alan sorulara cevap bulunmaya çalışılmıştır:

\section{Muhtemel Örgütlenme ve Öneriler İle İlgili Sorular}

1. Sürdürülebilirliği sağlamak adına Ayvalık'ta oluşturulacak bir Destinasyon Yönetim Örgütü'ne kimler dahil edilmelidir? Önerilerinizi sıralayınız.

2. Oluşturulacak Destinasyon Yönetim Örgütü'nün liderliğini hangi kurum/kuruluş veya işletmeler yapmalıdır? Nedenini açıklayınız.

3. Örgütün sürdürülebilirliği sağlamaya yönelik faaliyetleri (doğal, tarihi ve kültürel mirası koruma) neler olmalıdır?

4. Oluşturulacak Destinasyon Yönetim Örgütü'nün sürdürülebilirliği için finansal kaynaklar nasıl sağlanmalıdır? Önerilerinizi sıralayınız. 


\section{Veri Toplama Süreci}

Görüşülmek istenenler katılımcılar aranarak araştırmanın amacı bilgisi verilerek randevu talep edilmiştir. 2019 Ekim ve 2020 Şubat aylarında 4 ay katılımcıların görev yaptıkları yerlere gidilerek görüşmeler gerçekleştirilmiştir. Araştırma verileri; bu süreçte 9 kamu kurumu yetkilisi, 8 sivil toplum kuruluşu temsilcisi, 16 turizm işletmesi yetkilisi, 5 yerel halk ve 4 turist olmak üzere toplam 42 kişiden elde edilmiştir.

\section{Verilerin Analizi}

Görüşmelerde ses kaydı yapılmış ve daha sonra elde edilen ses kayıtları yazılı doküman haline getirilmiştir. Görüşülen katılımcılar $K 1, K 2, K 3$..... ve K42 şeklinde kodlanmıs, analizlerde bu kodlara yer verilmiştir. Verilerin toplanmasında veri yeterliliği tanımlanmış ve verilen cevaplarda herhangi bir yeni bilgiye ulaşılamıyor ise araştırmada doygunluğa ulaşılmıştır demektir (Morse, 1995, s.147). Araştırmada verilen cevaplar, bir noktadan sonra tekrar ettiği ve yeni bilgilere ulaşılamadığından çalışma 42 kişi ile tamamlanmıştır. Katılımcıların çalıştıkları pozisyon, çalışılan yıl, cinsiyet, yaş ve öğrenim durumları ile ilgili tanımlayıcı istatistiklere yer verilmiştir.

Yarı yapılandırılmış görüşme formundaki sorular 4 temaya göre hazırlanmıştır. Görüşme verileri kullanılarak içerik analizi ve betimsel analiz yapılmıştır. Çalışmanın geçerliliği için verilerin toplanması ve analizine ilişkin detaylı bilgi verilerek dış geçerliliğin arttırılması hedeflenmiştir. Mülakatlar yazılı dokümana dönüştürülmesinden sonra başka bir uzman tesadüfi 5 katılımcının ses kayıtları ile yazılı dokümanları karşılaştırmış ve analiz yapılacak yazılı dokümanların doğrulanması sağlanmıştır. Araştırmacı, analizinde farklı zamanlarda olguları aynı şekilde kodlamış ve zamana bağlı güvenilirlik sağlanmıştır. Ayrıca bir öğretim üyesinin de araştırma verilerini kodlaması istenmiş, araştırmadaki olguların farklı araştırmacıların aynı şekilde kodlanması \% 91 oranında ortaya çıkmış ve farklı kodlanan olguların iki araştırmacının birlikte kodlanması sağlanmıştır. İki araştırmacının bir olguyu aynı şekilde kodlaması gözleme bağh güvenilirlik şeklinde ifade edilmektedir (Yıldırım ve Şimşek, 2011, s.257). Böylece gözleme bağlı güvenilirlik de sağlanmıştır. Nitel araştırmalarda iç geçerlilik, bir olgunun olduğu gibi mümkünse doğrudan 
alıntılarla yansız bir şekilde aktarnlmasıdır (Yıldırım ve Şimşek, 2011, s.257). Araştırmanın iç geçerliliğini artırmak için katılımcıların yorumlarından doğrudan alıntılar yapılmıştır.

\section{Bulgular}

Araştırmanın bu bölümünde; turizm ve zeytin kenti olan Ayvalık'ı sürdürülebilir bir destinasyon olmasını sağlayacak öneriler geliştirmek ve sürdürülebilir destinasyon yönetimi modelini ortaya çıkarmak için verilerin analiz ve yorumlarına yer verilmiştir. Katılımcılar, sorulara cevap olarak fikirlerini, önerileri ve yorumlarını aktarmışlardır. Görüşme formunun ilk kısmında, demografik bilgilere ve sonraki bölümündeki cevapların detaylı analizleri sonucunda oluşturulan kod ve temalara yer verilmiştir.

Tablo 1'de katılımcılar K1, K2,...K3 şeklinde kodlanmıştır. Katılımcıların pozisyonları, çalışma yılı, yaş, cinsiyet ve öğrenim durumunu içeren profilleri yer almaktadır. Katilıcıların büyük çoğunluğunun (\% 90,47) erkek olduğu görülmektedir.

Tablo 1. Katılımcılarn Demografik ve Mesleki Özellikleri

\begin{tabular}{llllll}
\hline Kod & Mesleği & $\begin{array}{l}\text { Çalışma } \\
\text { Ylı }\end{array}$ & Yaş & Cinsiyet & $\begin{array}{l}\text { Öğrenim } \\
\text { Durumu }\end{array}$ \\
\hline K1 & Kamu Kurumu Yetkilisi & 17 & 37 & Kadın & Lisansüstü \\
\hline K2 & Kamu Kurumu Yetkilisi & 14 & 37 & Erkek & Lisansüstü \\
\hline K3 & Kamu Kurumu Yetkilisi & 26 & 52 & Erkek & Lisans \\
\hline K5 & Kamu Kurumu Yetkilisi & 23 & 43 & Erkek & Lisansüstü \\
\hline K6 & Kamu Kurumu Yetkilisi & 20 & 47 & Kadın & Lisans \\
\hline K7 & Kamu Kurumu Yetkilisi & 30 & 56 & Erkek & Lisansüstü \\
\hline K8 & Kamu Kurumu Yetkilisi & 25 & 50 & Erkek & Lisans \\
\hline K9 & STK Yetkilisi & 22 & 43 & Erkek & Lisans \\
\hline K10 & STK Yetkilisi & 35 & 56 & Erkek & Lise \\
\hline K11 & STK Yetkilisi & 30 & 55 & Erkek & Lisansüstü \\
\hline K12 & STK Yetkilisi & 35 & 58 & Erkek & Lisans \\
\hline K13 & STK Yetkilisi & 45 & 66 & Kadın & Lisans \\
\hline K14 & STK Yetkilisi & 37 & 69 & Erkek & Lisans \\
\hline K15 & STK Yetkilisi & 36 & 53 & Erkek & Lise \\
\hline K16 & STK Yetkilisi & 30 & 60 & Erkek & Lisans \\
\hline K17 & Otel Sahibi & 20 & 36 & Erkek & Lise \\
\hline K18 & Otel Sahibi & 30 & 50 & Erkek & Lisans \\
\hline K19 & Otel Sahibi & 12 & 31 & Erkek & Lisans \\
\hline K20 & Otel Sahibi & 30 & 50 & Erkek & Lisans \\
\hline K21 & Otel Sahibi & 17 & 35 & Erkek & Lisans \\
\hline K22 & Otel Sahibi & 31 & 51 & Erkek & Lise \\
\hline & & 22 & 40 & Erkek & Lisans \\
\hline
\end{tabular}


Tablo 1 - Devamı

\begin{tabular}{|c|c|c|c|c|c|}
\hline Kod & Mesleği & Çalışma Yılı & Yaş & Cinsiyet & Öğrenim Durumu \\
\hline K23 & Restoran Sahibi & 27 & 42 & Erkek & Lise \\
\hline K24 & Restoran Sahibi & 30 & 45 & Erkek & Ortaokul \\
\hline K25 & Restoran Sahibi & 17 & 51 & Erkek & Lise \\
\hline K26 & Seyahat Acenta Sahibi & 35 & 53 & Erkek & Lise \\
\hline K27 & Seyahat Acenta Sahibi & 34 & 51 & Erkek & Lise \\
\hline K28 & Gezi Teknesi ve Gemi Acentası Sahibi & 23 & 38 & Erkek & Lisans \\
\hline K29 & Sualtı Dalış Teknesi Sahibi & 15 & 35 & Erkek & Lisans \\
\hline K30 & Zeytin İşletmesi Sahibi & 10 & 25 & Erkek & Lise \\
\hline K31 & Zeytin İşletmesi Sahibi & 26 & 50 & Erkek & Lisans \\
\hline K32 & Zeytin İşletmesi Sahibi & 10 & 27 & Erkek & Lisansüstü \\
\hline K33 & Yerel Halk & 30 & 58 & Erkek & Lise \\
\hline K34 & Yerel Halk & 12 & 32 & Erkek & Lisans \\
\hline K35 & Kamu Kurumu Yetkilisi & 34 & 51 & Erkek & Önlisans \\
\hline K36 & Yerel Halk & 18 & 43 & Erkek & Lisans \\
\hline K37 & Yerel Halk & 22 & 46 & Kadın & Lisans \\
\hline K38 & Yerel Halk & 31 & 53 & Erkek & Önlisans \\
\hline K39 & Turist & 26 & 50 & Erkek & Lisans \\
\hline K40 & Turist & 35 & 60 & Erkek & Lisans \\
\hline K41 & Turist & 5 & 33 & Erkek & Lisansüstü \\
\hline K42 & Turist & 20 & 43 & Erkek & Lisans \\
\hline
\end{tabular}

Görüşülen kişilerin önemli bir bölümü $(\% 52,38) 50$ yaş ile üzerinde ve önemli bir kısmının da (\% 69,04) en az lisans mezunu olduğu görülmektedir. Katılımcıların çoğunluğu $(\%$ 57,14) özel sektörde çalışmaktadır. Araştırma sonucunda 4 araştırma sorusuna alınan cevapların düzenlenmiş hali aşağıdaki gibidir.

Tablo 2'de katılımcıların Ayvalık Destinasyon Yönetim Örgütü'nde yer alacak paydaşların belirlenmesine yönelik görüşlerini ifade ettikleri görüşmelerin analizi sonucunda ortaya çıkan kod ve temalar yer almaktadır.

Tablo 2. Destinasyon Yönetim Örgütünde Yer Alacak Paydaşlarnn Belirlenmesine Yönelik Katılımcı Görüşleri

\begin{tabular}{ll}
\hline Tema: 1 -Örgüt Modeli (45) & \\
\hline Alt Temalar & Kodlar \\
& \\
1.1. Kamu-Özel sektör ortaklığı & Kamu-Özel sektör ortaklığı (31) \\
& $\checkmark$ Tüm Kurumlar (26) \\
1.2. Özel sektör ağırlıkı & $\checkmark$ Belediye yeterli (5) \\
& Özel sektör ağırlıklı (12) \\
1.3. Hakem olmalı & $\checkmark$ Sadece turizm işletmeleri (9) \\
& $\checkmark \quad$ Esnaf olabilir (3) \\
1.4. Örgüte ihtiyaç yok & Hakem olmalı (1) \\
& Örgüte ihtiyaç yok (1)
\end{tabular}


Katılımcıların destinasyon yönetim örgütü paydaşlarına yönelik değerlendirmeleri dört alt temada toplanmıştır. Kodlamaların \% 69'u (31) kamu-özel sektör ortaklı̆gı alt temasındadır. Bu alt temada; tüm kurumların örgüte dahil edilmesi ile Belediyenin örgütte yer almasının yeterli olduğu ve diğer kurumların sadece destek vermesine yönelik ifadeler yer almaktadır.

Kodlamaların \% 27'si (12) özel sektör ă̆ırlıklı alt temasındadır. Bu alt temada; örgüt üyelerinin sadece turizm işletmelerinden oluşması ve kamunun destek vermesi ile esnafın da örgüte dahil edilmesi ifadeleri yer almaktadır.

Diğer bir alt tema olan hakem olmalı (\% 2) örgütte hakemlik görevini üstlenecek bir kişinin dahil edilmesini ifade etmektedir. Son alt tema olan örgüte ihtiyaç yok (\% 2) ise örgüt kurulmasına ihtiyaç olmadığını ve mevcut sistemin çeşitli düzenlemelerle etkinleştirilmesi gerektiğini ifade etmektedir.

Ayvalık Destinasyon Yönetim Örgütü'nde yer alacak paydaşlara yönelik katılımcı söylemi şu şekildedir:

- K12: Bu süreçte tüm paydaşların olması gerekiyor. Bu örgütte Ticaret Odası, Esnaf ve Sanatkarlar Odası, Belediye Başkanlığı, turizm işletmeleri, Kültür ve Turizm Bakanlığı, Tarım Bakanlığı ve Ayvalıklıları temsilen STK'lar yer almalıdır. Bence bütün bu paydaşlarla beraber beyin fırtınası yapılarak karar verilmelidir. Sonuçta burası, Ayvalıklıların şehridir. Dolayısıyla yapılacak etkinlikler, önce onlara fayda sağlamak için planlanıyor. Hem kamu hem özel sektör olmalıdır. Yani herkesin fikri alınarak bu örgütün oluşturulması gerekiyor. Eğer biz mükemmele ulaşmak istiyorsak bazen bir çocuktan da o mükemmellik adına ipucunu yakalayabiliriz.

Tablo 3'te katılımcların Ayvalık Destinasyon Yönetim Örgütü liderinin belirlenmesine yönelik görüşlerini ifade ettikleri görüşmelerin analizi sonucunda ortaya çıkan kod ve temalar yer almaktadır.

Tablo 3. Destinasyon Yönetim Örgütü Liderinin Belirlenmesine Yönelik Katılımcı Görüşleri

\begin{tabular}{ll}
\hline Tema: 2-Liderin Belirlenmesi (42) & \\
\hline Alt Temalar & Kodlar \\
\hline \multirow{3}{*}{ 2.1. Kamu Kurumu } & Kamu Kurumu (27) \\
& $\checkmark$ Belediye (15) \\
2.2. Özel sektör & $\checkmark$ Kaymakamlık (8) \\
& $\checkmark$ İ Kültür ve Turizm Müdürlüğü (2) \\
& $\checkmark$ Turizm Akademisyeni (2) \\
\hline
\end{tabular}


2.3. Yuvarlak masa yöntemi

2.4. Farketmez, seçilmeli
Özel sektör (11)

$\checkmark$ Turizm işletmesi (9)

$\checkmark$ Seçimle belirlenmeli(2)

Yuvarlak masa yöntemi (3)

Farketmez, seçilmeli (1)

Katılımcıların örgüt liderinin belirlenmesine yönelik değerlendirmeleri dört alt temada toplanmıştır. Kodlamaların \% 64'ü (27) kamu kurumu alt temasındadır. Bu alt temada; hangi kamu kurumlarının örgüte liderlik etmesi gerektiğine yönelik ifadelere sırasıyla yer verilmiştir. Kodlamaların yaklaşık \% 26'sı (11) özel sektör alt temasındadır. Bu alt temada; destinasyonda faaliyet gösteren bir turizm işletmesinin veya özel sektörden seçimle belirlenecek bir işletmenin örgüte liderlik etmesine yönelik ifadeler yer almaktadır.

Diğer bir alt tema olan yuvarlak masa yöntemi (\% 7) liderlik yerine paydaşların eşit olduğu yuvarlak masa yöntemiyle kararların alınmasını ifade etmektedir. Son alt tema olan farketmez, seçilmeli (\% 3) ise liderin kamu veya özel sektörden seçimle belirlenmesini ifade etmektedir.

Destinasyon Yönetim Örgütü liderinin belirlenmesine yönelik katılımcı söylemi şu şekildedir:

- K11: Bu bir devlet kurumu olmadığından lider yerine yuvarlak masa toplantısı olabilir. Herkesin eşit ve demokratik hareket edebileceği bir yapı olabilir. Örgütün aldığı kararlar ile turizmin amaç değil araç olarak kullanılması önlenmelidir. Önemli olan destinasyon olarak karar alabilmektir. Yeni bir örgüt kurmak yerine AYTUGEB, herkesin katk1 sağladığı ve herkesin denetlediği bir yer olabilir. AYTUGEB'i; Kaymakamlık veya Belediye denetleyebilir. Bu örgüt; kurumlardan talepte bulunabilir, işletmelere zorlayıcı gücü ile şekil verebilir ve turizm sektörünün Ayvalık'taki danıştayı olabilir. Yani işletmeler oraya yapılması gereken ile ilgili danışırlar ve o da bir karar verebilir.

Tablo 4'te katılımcıların örgütün Ayvalık'ta sürdürülebilirliğin sağlanması için yapması gereken faaliyetlere yönelik görüşlerini ifade ettikleri görüşmelerin analizi sonucunda ortaya çıkan kod ve temalar yer almaktadır. 
Tablo 4. Örgütün Sürdürülebilirlik Faaliyetlerine Yönelik Katılımcı Görüşleri

\begin{tabular}{ll}
\hline Tema: 3 - Sürdürülebilirlik Faaliyetleri (95) & \\
\hline Alt Temalar & Kodlar \\
\hline & Tarihi ve kültürel mirası koruma (40) \\
& $\checkmark$ Tarihi bina restorasyonu (20) \\
3.1. Tarihi ve kültürel mirası koruma & $\checkmark$ Envanter çalışması (8) \\
& $\checkmark$ Belediyenin çalışmaları (4) \\
3.2. Doğal mirası koruma & $\checkmark$ Sokak iyileştirmesi (4) \\
& $\checkmark$ Örgütlenme (2) \\
& $\checkmark$ Tanıtım (2) \\
3.3. Halkın bilinçlendirilmesi & Doğal mirası koruma (25) \\
& $\checkmark$ Koruma faaliyetleri (17) \\
& $\checkmark$ Temizliğe özendirme (4) \\
3.4. Sadece turizmin yönetilmesi & $\checkmark$ Envanter çalışması (2) \\
& $\checkmark$ Örgütlenme (2) \\
& Halkın bilinçlendirilmesi (22) \\
& $\checkmark$ Eğitim (18) \\
& $\checkmark$ Kent aidiyeti (3) \\
& $\checkmark$ Zeytinyağı tüketimi \\
& Sadece turizmin yönetilmesi (8)
\end{tabular}

Katılımcların örgütün sürdürülebilirlik faaliyetlerine ilişkin değerlendirmeleri dört alt temada toplanmıştır. Kodlamaların \% 42'si (40) tarihi ve kültürel mirası koruma alt temasındadır. Bu alt temada; tarihi binaların kamu eliyle restore ettirilmesi, restorasyonda bina çevresinin kapatılması, GMKA veya Kültür ve Turizm Bakanlığından kaynak sağlanması, tarihi yapıların aynı renge boyanması, eski insanların video kaydı alınması, anıt ağaçların koruma kanunu çıkarılması, bina dış cephesi ile tabelada sokak iyileştirmesi, turist rehberi sayısının artırılması, merkezin trafiğe kapatılarak turistlere kulaklık sesli yayın ile tarih anlatılması, Belediyenin; destinasyon tanıtımına ağırlık vermesi, tarihi sokaklarda park etme yasağı koyması, ev pansiyonculuğunu kayıt altına alması ve turizm müdürlüğ̈̈ kurması ifadeleri bulunmaktadır.

Kodlamaların \% 27'sini (25) doğal mirası koruma alt temasındadır. Bu alt temada; sit alanları, doğal güzelliklerin korunmasıyla turistler ile yerel halkın doğayı kirletmesinin ve tarım arazilerinin imarının önlenmesi, örnek destinasyonların incelenip koruma kullanma dengesi planı hazırlanması, piknik alanları denetiminin artırılması, "Ayvalık'1 Ayvalık' ta yaşayan korur" sloganıyla temizlik kampanyaları düzenlenmesi, sokaklarda kente özgü renk kullanılması, Doğa ve Milli Parklar temsilcisinin DYÖ'ne dahil edilmesi ifadeleri bulunmaktadır. 
Diğer alt tema halkın bilinçlendirilmesi ise kodlamaların \% 23'ünü (22) oluşturmuştur ve koruma, sürdürülebilirlik eğitimleri verilmesi, UNESCO bilgilendirme çalışmaları, sosyal medyada kısa film, vurucu reklam ile bilinçlendirme, kent aidiyetinin oluşması ile tarihi restorasyon için halkın bilinçlendirilmesi, tarihi yapı hikayelerinin derlenmesi, zeytinyağının sağlığa faydaları anlatılması ifadeleri bulunmaktadır. Ayrıca sadece turizmin yönetilmesi (\% 8) alt teması ise örgütün Ayvalık turizm faaliyetlerini organize etmesini ve koruma çalışmalarının ise ilgili kurumlar tarafından yapılması gerektiğini (8 katılımc1) ifade etmektedir.

Örgütün Ayvalık'ta sürdürülebilirliği sağlamak için yapması gereken faaliyetlere yönelik katılımcı söylemi şu şekildedir:

- K1: En başta destinasyonun doğal, tarihi ve kültürel miras envanterinin çıkarılması, master planının hazırlanması ve sürdürülebilir olmasını sağlayacak faaliyetler belirlenmesi gerekiyor. Bu amaçla bu miras koruma altına alınarak geliştirilmeye çalışılır, müzeler oluşturulabilir, bu alanların korunması için ofisler açlır ve ilgili kişiler ofislerde görevlendirilir. Bina yapılaşmasının vizyonlu ve nitelikli oteller inşa ederek turizme katkı sağlayacak şekilde yapılması teşvik edilebilir. Avrupa'daki doğa konseptli otellerde arka bahçede atlara binerek spor yapıyorlar ve isteyen mutfakta kendi yemeğini hazırlıyor. Bu tür doğal yaşamı seven turistlerin tercih edebileceği tesisler inşa edilebilir. Arka bahçesinde folluktan yumurtanı alabileceğin, zeytin döneminde ise zeytin hasadına katılabileceğin ve oradaki yerel imkanların sunulacağ 1 tesisler olabilir.

Tablo 5'te katılımcların örgütün finansal kaynak sağlamasına yönelik görüşlerini ifade ettikleri görüşmelerin analizi sonucunda ortaya çıkan kod ve temalar yer almaktadır.

Tablo 5. Örgütün Finansal Kaynak Sağlamasına Yönelik Katılımcı Görüşleri

\begin{tabular}{ll}
\hline Tema: 4-Finansal Kaynak Sağlama (58) & \\
\hline Alt Temalar & Kodlar \\
\hline & \\
4.1. Aidat & Aidat (38) \\
& $\checkmark$ Turizm işletmeleri (25) \\
& $\checkmark$ Esnaf dahil edilebilir (5) \\
& $\checkmark$ Şeffaf olma (5) \\
& $\checkmark$ Tutarın belirlenmesi (3)
\end{tabular}




\begin{tabular}{ll}
\hline & \\
& Kurumlar (20) \\
4.2. Kurumlar & $\checkmark$ Düzenlemeler (6) \\
& $\checkmark$ Projeler (4) \\
& $\checkmark$ Plaj (3) \\
& $\checkmark$ İşletme kurulması (2) \\
& $\checkmark$ Festival (2) \\
& $\checkmark$ Müze geliri \\
& $\checkmark$ Sponsorluk \\
\hline
\end{tabular}

Katılımcıların finansal kaynak sağlanmasına yönelik değerlendirmeleri iki alt temada toplanmıştır. Kodlamaların \% 66's1 (38) aidat alt temasındadır. $\mathrm{Bu}$ alt temada; otellerden yatak başına ücret ile diğer turizm işletmelerinden yıllık aidat alınması, fuara katılan işletmelerden ücret alınması, aidatın yasal yaptırımı olması, danışmanlık hizmetiyle veya tanıtım broşürü satarak işletmelerden kaynak sağlanması, esnaftan sembolik ücret alınması, kaynak kullanımının şeffaf açıklanmasıyla güven verilmesi ve aidat tutarını Ticaret ile Esnaf Odası veya işletmelerin belirlemesi ifadeleri bulunmaktadır.

Diğer alt tema Kurumlar ise kodlamaların \% 34'ünü (20) oluşturmuştur. $\mathrm{Bu}$ alt temada; kurumlar ve turizm işletmelerinin eşit katkı sağlaması, Kaymakam liderliğinde kent turizm gelirinin belli yüzdesinin örgüte aktarılması, Bakanlıkların hibe destek projelerine başvurulması, halk plajı, müzeler veya festival sponsor stant gelirinin bir kısmının verilmesi, örgütün işletmeler kurması, projelerle sponsor aranması ve Odaların üyelerinden kupon karşılığ katkı payı toplamasına yönelik ifadeler yer almaktadır.

Örgütün finansal kaynak sağlamasına yönelik katılımcı söylemi şu şekildedir:

K33: Finansal kaynaklarının büyük bir kısmı, turizm yelpazesindeki bütün turizm işletmecileri tarafından paylaşılarak karşılanmalıdır. Yerel yönetim, Odalar ve diğer kurumların da bütçe ayırması gerekiyor. Kaynakların tamamını Odaların veya yerel yönetimlerin karşılanmasını doğru bulmuyorum. O zaman, örgüt sürdürülebilir olmuyor. Hangi sektör para kazanıyorsa bu işten herkes taşın altına elini koymalı. Bu şehre en iyi bakacak insanlar, en başta turizm işletmeleri olmalı. Turizm işletmelerinin; şehrin temizliği, görseli, doğası ve her şeyine gözleri gibi bakmaları gerekiyor. Çünkü o işten para kazanıyorlar ve birçok insan da bu işletmelerde çalışarak o işten ekmek yiyor. O yüzden esnaf da dahil özel sektörün bu şehre gözü gibi bakması gerekiyor. 


\section{Ayvalık'ın Sürdürülebilir Destinasyon Yönetimi için Model Önerisi}

Şekil 1'de "Ayvalık Destinasyonu Yönetim Örgütü Model Önerisi" görülmektedir. Şekil oluşturulurken yapılan saha araştırmalarında destinasyonda turizmden etkilenen ve turizmi etkileyen 42 paydaş ile yapılan görüşmelerden elde edilen veriler, yazarın gözlemleri, literatür taramasından elde edilen teorik çerçeveye ilişkin ikincil veriler ve Gökdeniz'in (2019), kitabında yer alan Ayvalık Destinasyon Yönetim Örgütü Modelinden yararlanılmıştır. 


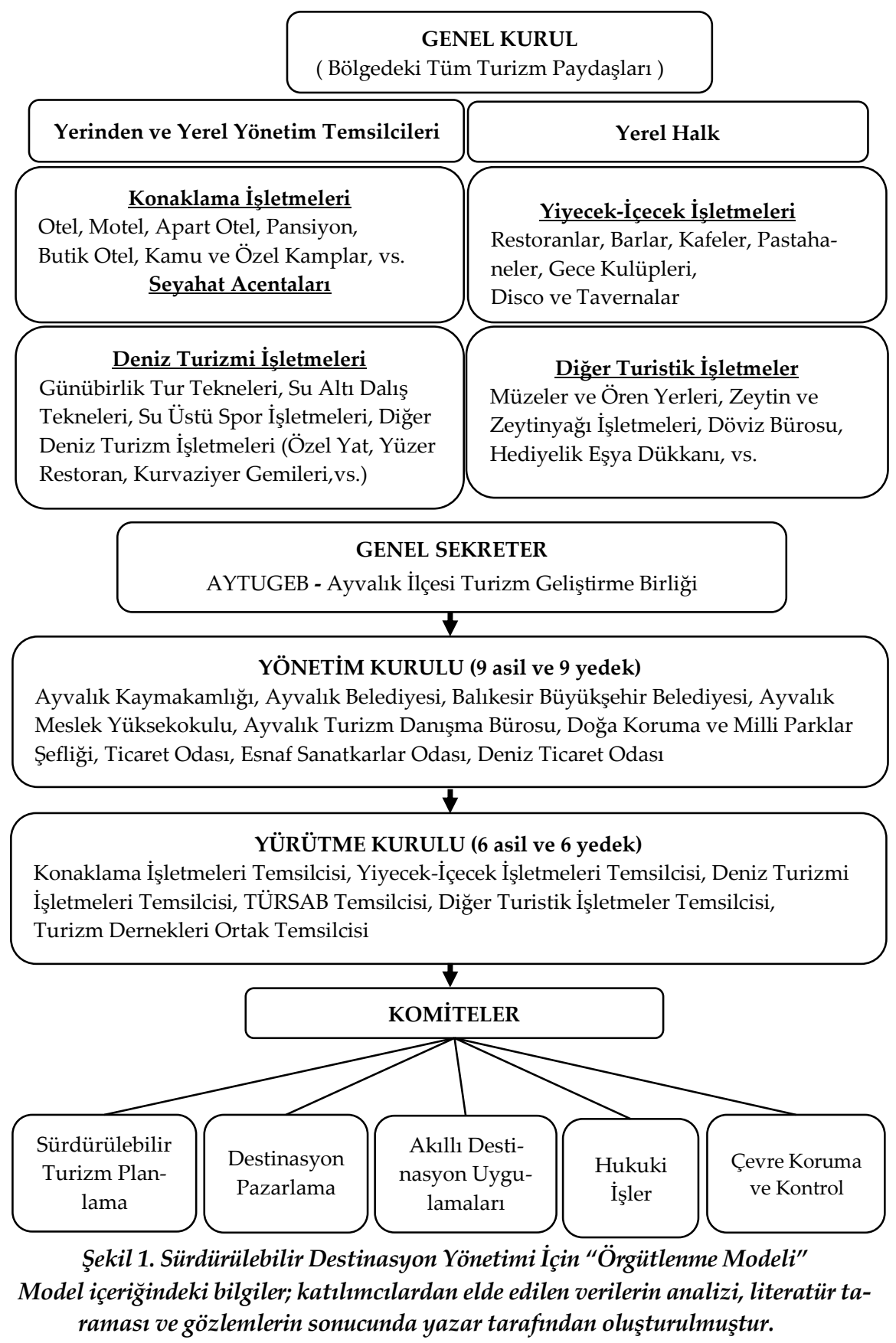


Bu modelde belirtilen Resmi Kurumlar ile Oda Başkanlıkları; yönetim kurulunun doğal üyeleridir. Her komite, üç üye ve bir başkandan oluşmaktadır. Bölgedeki paydaşların yer aldığı genel kurul tarafından üç yılda bir yapılacak toplantıda yürütme kurulu, komitelerin üyeleri ve başkanları seçim yaparak belirlenir. Paydaşlar, bilgi sahibi olduğu ve faaliyet gösterdiği sektörü temsil eden komitelerde üye veya başkan olarak seçme ve seçilme hakkına sahiptir. Komiteler; Sürdürülebilir Turizm Planlama, Destinasyon Pazarlama, Akıllı Şehir Teknolojisi, Hukuk İşleri, Çevre Koruma ve Kontrol olmak üzere beş gruba ayrılmıştır. Aynı şekilde turizm işletmeleri, yürütme kurulunda grup temsilcisi (konaklama işletmeleri, yiyecek içecek işletmeleri, deniz turizmi işletmeleri ve diğer turistik işletmeler) olarak seçme ve seçilme hakkına sahiptirler.

Ayvalık Kaymakamlığı, Balıkesir Valiliğiyle ve Ayvalık Belediye Başkanlığı ise Balıkesir Büyükşehir Belediye Başkanlığıyla iletişimi sağlayarak köprü görevi göreceklerdir. Bu Kurumlar, örgütün resmi işlemlerinde, hukuksal süreçlerindeki destekleri ile yönetimin sürdürülebilir ve etkili olmasını sağlayacaklardır. Yapılacak çalışmaların işleyiş̧inde sorun çıktığında ilgili Bakanlıklar ile görüşerek işlerin sorunsuz ilerlemesinde etkili olacaklardır.

Genel sekreter; kurullar, komiteler ve turizm paydaşlarını kapsayacak şekilde tüm işleyişin koordinasyonun sağlamasından sorumlu olacaktır. Genel Sekreter, 11 yıldır destinasyonda faaliyet gösteren Ayvalık İlçesi Turizm Geliştirme Birliği (AYTUGEB) olabilir. Birlik ile Ayvalık Turizm Danışma Bürosu sektörde yaşadıkları deneyimlerini paylaşarak gerekli turizm vizyon ve stratejilerinin oluşumuna katkı sağlayabilir. AYTUGEB; Ayvalık'taki tüm turizm işletmelerine hitap etmek amacıyla kurulan bir çatı örgütüdür. Bu birlik, yerel yönetimden belirli bir destek sağlamasına karşın turizm işletmelerinden yeterli desteği alamadığı için verimli çalışmalar yapamamıştır.

Komiteler, yürütme kurulu üyeleriyle birlikte yaptıkları çalışma sonuçlarını genel sekreter ile paylaşmalıdır. Genel sekreter, yürütme kurulu ve komite başkanları; bu konuları daha da olgunlaştırıp uygulanabilir hale getirdikten sonra yönetim kuruluna gerekçeleriyle beraber sunarak işleyişe katkı sağlamalıdır. Yönetim kurulu, çalışma sonucunda uygulanması önerilen proje ile işleri destinasyona ve örgütün mevzuatına uygunluğuna oy çokluğuyla karar verir.

Örgütün finansal kaynakları kamu kurumları ve özel sektör tarafından sağlanabilir. GMKA ile Bakanlıklara hibe destek projesi yazılarak kaynak 
sağlanabilir. Konaklama tesislerinden yatak başına belli bir ücret ve diğer turizm işletmelerinden yılda bir kere üyelik aidatı toplanabilir. Belediye, imkanları elverdiği ölçüde gelirinin bir kısmını (AYTUGEB'in tüzüğüne göre) turizmi geliştirmek için örgüte aktarabilir. Bunların yanı sıra örgütte yer alan kurum ve kuruluşlar, örgüte fayda sağlamak için bağlı oldukları bakanlıkların desteklerine başvurabilirler.

Gündem asayiş ve güvenlik konuları olduğunda; İlçe Emniyet Müdürlüğü, İlçe Jandarma Komutanlığı ve Sahil Güvenlik Kuzey Ege Grup Komutanlığı toplantılara davet edilebilir. Bunun yanı sıra temizlik ile hijyen için İlçe Tarım ve Orman Müdürlüğü, deniz ile havuz temizliği ve kapalı alanda sigara kullanımı denetimi için İlçe Sağlık Müdürlüğü, kanalizasyon ve su gibi konular gündemde yer alıyorsa Balıkesir Su ve Kanalizasyon İdaresi (BASKİ) Ayvalık Şube Müdürlüğü yapılacak toplantılara davet edilebilir.

DYÖ, yapılacak ilk toplantısında sürdürülebilir ve stratejik bir turizm planı ile bu planın nasıl ve ne kadar sürede uygulanacağını gösteren eylem planlarını hazırlamalıdır. Destinasyona gelen yerli ve yabancı turist sayıları göz önüne alınıp hedef kitle belirlendikten sonra destinasyonun kısa ve uzun vadeli olarak nasıl pazarlanacağı, yurt içinde ve yurt dışında hangi fuarlara katılım sağlanacağı gibi konular oy çokluğuyla karara bağlanmalıdır.

\section{Tartışma ve Sonuç}

Ayvalık; Ege'nin pırıl pırıl denizini, uçsuz bucaksız kumsallarıyla kucaklayan, tarihi ve doğasıyla tadına doyamayacağınız bir Batı Anadolu şehridir. Denizin üzerine serpilmiş gibi duran Adalar, altında benzersiz mercan resifleri ve yeşille bütünleşmiş koylarıyla eşsiz bir doğa harikasıdır (www.ayvalikturizmdanismaburosu.ktb.gov.tr).

Bu araştırmanın amacl; turizm ve zeytin kenti olan Ayvalık'1 sürdürülebilir bir destinasyon olmasını sağlayacak öneriler geliştirmek ve Ayvalık'ın sürdürülebilir destinasyon yönetimi için bir model geliştirmektir. Görüşmeler, gözlemlerden ve literatürden yola çıkarak Ayvalık'ın Sürdürülebilir Destinasyon Yönetimi için “Örgütlenme Modeli” ortaya konmuştur.

Yerel halk, turizm işletmeleri ile onları temsil eden STK'lar ve diğer paydaşların yönetime katılımının istenilen düzeyde olmadığı görülmüş̧ür. Turizmin tek elden yönetilmesiyle güçlü ve kararlı adımlar atılması gerekmek- 
tedir. Bu amaçla kurulacak DYÖ, önemli bir araç olacaktır. DYÖ'nün aynı çalışanların sendikası gibi işletmelerin haklarını koruyan bir örgüt olması gerekmektedir. Sürdürülebilir turizmin önünde bir sorun olduğunda örgütün işletmelerden önce yerel yönetime veya ilgili kurumlara başvurması, işletmeler ile birlikte hareket etmesi, gerektiğinde işletmeden daha çok işletme hakkını araması ve sorunlara çözüm bulması gerekmektedir. Merkezi ve yerel yönetim yetkililerinin de örgütlenme temelinin sağlamlığı için paydaşları bu örgüte yönlendirmeleri, destek ve güven vermeleri sağlanmalıdır. Örgütlenmeyle yapılacak sürdürülebilir turizm çalışmaları; yerel halkın yaşam kalitesini iyileştirir, turist memnuniyetini artırır, bakımsız kalmış birçok değer ortaya çıkartılarak ekonomik fayda oluşturulur ve gelecek nesillere kalması sağlanır.

Alan yazında bu araştırma sonuçlarına benzer sonuçlara ulaşan, örgütlenmenin önemi ve destinasyonların sürdürülebilir yönetilmesi için DYÖ’lerinin oluşturulması gerekli olduğunu ortaya koyan çalışmalar bulunmaktadır. Bunlardan Yoon (2002, s.165), DYÖ'lerin yerel yönetimlerin desteği ile "kolaylaştırıcı", destinasyon pazarlamada "liderlik" ve farklı hizmet yatırımlarını "planlama" gibi önemli rollerini belirtmiştir. David ve Tozser (2009, s.84), DYÖ'nün faaliyetlerini turistlere iyi bir tatil, halka ekonomik avantaj için bağımsız bir örgütle uzmanlar tarafından yürütmesi gerektiğini belirtmiştir. Bununla birlikte Pearce ve Shaenzel (2013, s.144), Genç (2013, s.99) ve Adeyinka-Ojo, Khoo-Lattimore ve Nair (2014, s.161), destinasyonlarda kaynakların yönetimi, destinasyon markası yaratılması, turistlerin destinasyon sadakati kazanması gibi rollerin yerine getirilmesi ve paydaş işbirliği için Yerel DYÖ’lerin kurulması gerektiği sonucuna ulaşmışlardır.

Araştırma sonuçlarından yola çıarak sürdürülebilir turizmin bölgede etkili şekilde uygulanması ve sürdürülebilir destinasyon oluşturulması için merkezi ile yerel yönetime, destinasyonu pazarlayanlara, turizm işletmelerine ve gelecekte bu konuda araştırma yapacak akademisyenlere önerilerde bulunulmuştur.

“Ayvalık Uzun Devreli Gelişme Plan"ında turizm faaliyetlerinin nasıl uygulanacağına yer verilmemiştir. Doğa Koruma ve Milli Parklar Şefliği ve ilgili Kurumlar, koruma kullanma dengesini gösterecek bir eylem planını hazırlayabilir. Bu plan ve turist sayılarına göre uzun devreli gelişme planı revize edilebilir. Ayvalık, "Endüstriyel Peyzaj" alanında UNESCO Dünya Mirası Geçici Listesi'ndedir. Kültürel destinasyon imajı için doğal, tarihi ve kültürel 
kaynaklar ile UNESCO ambleminin olduğu tek sayfa tanıtım hazırlanarak işletmelere dağıtılabilir. Ayvalık merkez, Cunda ve Sarımsaklı' daki taşıma kapasitesi akademik çalışmalarla belirlenerek sınırın aşıldığı saatlerde destinasyona girişler sınırlanabilir.

Mimari yapılar, bir kentteki korunmuş tarihin simgeleridir. 2030 tarihi yapıya sahip olan Ayvalık, Türkiye'de en fazla tescilli yapıya sahip ilçelerden biridir (Bezirgan ve Kömür, 2020, s.307). 2018 yılında Bölge Koruma Kurulu kurulmuş olsa da Bölge Koruma Kurulu kuruluna yapılan restorasyon başvuruları, yavaş sonuçlanabilmekte ve yatırım yapacak girişimciler olumsuz etkilenebilmektedir. Bu amaçla Ayvalık Belediyesi bünyesinde tarihi yapıları, mimari dokuyu, binalardaki genel bozulmaları bilen bir birim kurulabilir. İlgililer, Bölge Koruma Kuruluna başvurmadan önce bu birime projesinin uygunluğu ile ilgili danışabilir.

Kültürel mirasın korunması için bölge kültürüne hakim yerel halkla görüşülebilir ve anıları kayıt altına alınarak "Yaşayan Ayvalık" arşivi oluşturulabilir. Kültür ve Turizm Bakanlı̆̆ı ve Halk Eğitim Merkezinin vereceği eğitimlere turizm personelini teşvik etmek için sınavlar yapılarak her alanda en iyilere ödüller verilebilir. Kaymakamlık başkanlığında en iyi turizm işletmelerini belirleme komisyonu kurulabilir. İlgili Kurumlar, kendi alanlarındaki en iyileri belirler. Her yıl etkinlikle en iyiler duyurulabilir ve medya davet edilerek destinasyona dikkat çekilebilir. Turizm işletmeleri arasında futbol, voleybol turnuvaları ve gözü kapalı şekilde yöresel ot ismini bilme yarışmaları düzenlenerek kazanan takımlara ödüller verilebilir.

Bu çalışma; daha önce bu konudaki çalışma sayısının az olması nedeniyle nitel araştırma yöntemleriyle gerçekleştirilmiştir. Sadece Ayvalık turizm paydaşları ile sınırlandırılmış ve sonuçları genellenememiştir. Bir diğer sınırlılık ise verilerin Ekim 2019 - Şubat 2020 tarihlerinde toplanmasıdır. Ancak bu araştırma; turizmden gelir sağlayan Ayvalık ve diğer kentlerde uygulanabilecek bir "Örgütlenme Modeli" oluşturması açısından büyük önem arz etmektedir. Modelin oluşturulması için sadece literatürden faydalanılmamış ve tüm paydaşların ihtiyaçlarına uygun model geliştirilmiştir. Sonraki çalışmalarda bu çalışma sonuçları dikkate alınarak farklı destinasyonlar için model oluşturulabilir. Böylece turizm örgütlenmelerinin daha sağlıklı oluşturulmasıyla turizm planlamasına katkı sağlanabilir. Destinasyonlar karşılaştırılarak farklılıklar belirlenebilir veya daha geniş bölgeyi kapsayan bölgesel bir yönetim örgütü modeli de oluşturulabilir. 


\title{
EXTENDED ABSTRACT
}

\section{A Model Proposal For Sustainable Destination Management: The Case Of Ayvalık}

\author{
Yakup Dinç - Taner Kömür - Mehmet Oğuzhan İlban \\ Balıkesir University
}

Destinations need to conserve natural and cultural resources by using in a controlled manner and attach importance to sustainable tourism to be able to obtain competition advantage. At this point; organizing among the stakeholders consisting destination management is very important for shared decision making and carrying out necessary functions such as product development, visitor managemet, destination marketing, creating common competitive power, lobbying, market regulation, crisis management and finding financial resource.

The purpose of research is to develop of suggestions that provides Ayvalık, tourism and olive oil city, to become more sustainable destination, conveying of things to do to the stakeholders and develop a model to manage Ayvalık as a sustainable destination. The model developed in this study is aimed to apply in Ayvalık and help new researchs that will be implemented in Ayvalık and other destinations in future.

In this research, semi-structured interview technique has been performed. Data consists of comments of participants and author's observations. Within research, forty-two stakeholders which are under the categories of centralized administration, local administration, private sector, non-governmental organizations (NGOs) and other (local community, tourists, etc.) have been interviewed. Descriptive and content analyses have been performed in analysing of the data. "Organization Model" for sustainable destination management of Ayvalık has been put forward based on findings, observations and literature search.

Codetermination of locals, tourism establishments and NGOs are not enough. A Destination Management Organization (DMO) should be established to be able to take joint action of stakeholders. And this DMO should act as a labour union by defending establishments' rights, apply 
for local administration and related bodies, solve problem by seeking establishments' rights more than them. It should be given a clear message to tourists for a strong destination image and be implemented holistic destination marketing approach.

Public enterprises and non-governmental organizations stated in the proposed model are member as of right of the board of management. Each committee consists of 3 member and 1 president. Executive board, members and president of the committees are identified with election every 3 years in the general assembly consisting of all the stakeholders in the destination. Stakeholders have an right to void and stand as a candidate of member or president at election of committee in the field which they have knowledge of and carry on a business. Committees are separated into 5 groups: Sustainable Tourism Planning, Destination Marketing, Smart City Technologies, Legal Affairs, Environment Protection and Control. Likewise, the tourism establishments have an right to void and stand as a group representative of executive board member (Accommodation establisments, food and drink establishments, marine tourism establishments and other touristic establishments).

Secretary general is responsible of the coordination of all the processes including boards, committees and tourism stakeholders. Secretary general can be Ayvalık Tourism Development Union (AYTUGEB) acting in the region for 11 years.

Financial resources of this organization can be met by public enterprises and private sector. Besides they can be provided by writing projects to development agency of the the region (GMKA) and related ministries. Certain fee per bed from the accommodation facilities and certain fee per year from other tourism establisments can be collected. The municipality can transfer certain amount of its revenue to the organization within the bounds of possibility (As stated in the union charter of AYTUGEB).

In the first meeting which will be hold by Destination Management Organization should be prepared sustainable and strategic tourism plan of the destination, action plans explaning how and how long time this plan will be implemented. First it should be determined the target market by taking into account the number of domestic and foreign tourists visiting the destination. After that the issues of how the destination will be marketed in the short and long term, which domestic and abroad fairs will be 
attended as a destination should be decided by majority of votes of the stakeholders.

"Organization Model" for sustainable destination management of Ayvalık has been put forward based on findings, observations and literature search. Destinations need to conserve natural, historical, cultural resources and provide public participation by raising awareness for sustainability of destination. Sustainable management and marketing activities need to be carried out on the basis of destination.

The authorities of centralized and local administration need to support the DMO and direct the stakeholders to this organization. Performing of sustainable tourism works; enhances the quality of life and tourist satisfaction, achieves economic benefit by revealing lots of values and provides these values handing down to the next generations. A municipality department which knows historical structures, architectural texture and general problems in buildings can be established. This department checks the restoration projects of the historical buildings and thus the process of restoration applications can speed up.

Based on the research results, it has been made suggestions to implement effectively sustainable tourism in the region.

Long-term development plan can be revised to organize tourism activities considering number of tourists. Carrying capacity of destination can be determined and visitors can be restricted in the hours exceeding this limit.

Locals having knowledge of region culture can be interviewed and recorded their memories to conserve cultural heritage by constituting city records. Ayvalık is an UNESCO World Cultural Heritage. So a flyer informing that feature can be prepared and it can be delivered to all the tourism establishments to promote cultural destination image.

Tourism and environment training should be provided for tourism establishments to raise awareness. A commission consisting related bodies under the leadership of district governership can determine the best tourism establishments in the region according to certain criteria. And these establishments can be declared through an event every year and drawed attention to destination via media. Football, volleyball tournaments and competitions to guess blindingly the name of the local herbs can be organized among the tourism establishments and awarded winner teams. 


\section{Kaynakça / References}

Adeyinka-Ojo, S. F., Khoo-Lattimore, C. and Nair, V. (2014). A framework for rural tourism destination management and marketing organisations. ProcediaSocial and Behavioral Sciences, 144(144), 151-163.

Ali, F., Hussain, K., Nair, V. and Nair, P. K. (2017). Stakeholders' perceptions \& attitudes towards tourism development in a mature destination. Turizam: međunarodni znanstveno-stručni časopis, 65(2), 173-186.

Artun, C. (2016). Sürdürülebilir turizmin başarı koşulları ve etkin bir turizm politikasının belerilenmesine etki eden etmenler. H. Çeken (Edi.), Sürdürülebilir turizm içinde (s. 117-138). Ankara: Detay Yayıncılık.

Bezirgan, M. ve Kömür, T. (2020). Konaklama arz yapısı bakımından turistik destinasyonlarda diş çevre analizi: Ayvalık örneği. Afyon Kocatepe Üniversitesi Sosyal Bilimler Dergisi, 22(1), 295-311.

David, L. and Tozser, A. (2009). Destination management: necessity and tasks of tourism destination management in Hungary. APSTRACT: Applied Studies in Agribusiness and Commerce, 5(1033-2016-83957), 81-84.

Demircan, Ş. (2016). Sürdürülebilirliğin boyutları. H. Çeken (Ed.), Sürdürülebilir turizm içinde (s. 11-23). Ankara: Detay Yayıncılık.

Fyall, A. and Garrod, B. (2019). Destination management: a perspective article. Tourism Review, 75(1), 165-169.

Genç, K. (2013). Sürdürülebilir destinasyon yaratma sürecinde örgütlenmenin önemi: Çanakkale turizmi üzerine bir araştırma. Yüksek Lisans Tezi. Çanakkale: Çanakkale 18 Mart Üniversitesi, Sosyal Bilimler Enstitüsü.

Gökdeniz, A. (2019). Ayvalık stratejik turizm planı (2019-2023) ve destinasyon yönetim örgütü modeli. Ankara: Detay Yayıncilı.

Gündüz, C. (2016). Sürdürülebilir turizmin ilke, amaç ve hedefleri. H. Çeken (Editör), Sürdürülebilir turizm içinde (s. 104-115). Ankara: Detay Yayıncllı.

İlban, M. O. (2019). 2023 Türkiye turizm stratejilerinde kilit unsur: Destinasyon yönetimi. General Management Turizm \& Yönetim Dergisi. 132, 82-84.

İslamoğlu, H. ve Alnıaçı, Ü. (2016). Sosyal bilimlerde araştırma yöntemleri, 5. Baskı. İstanbul: Beta Yayıncilı.

Morse, J. M. (1995). The Signifance of Saturation, Qualitative Health Research, 5(2), 147-149.

Özdemir, G. (2014). Destinasyon yönetimi ve pazarlaması. Ankara:Detay Yayıncllı.

Pearce, D. (2016). Interdependent destination management functions. Tourism Recreation Research, 41(1), 37-48. 
Pearce, D. G. and Schänzel, H. A. (2013). Destination management: The Tourists' Perspective.Journal of Destination Marketing \& Management, 2(3), 137-145.

Şanlı̈z-Özgen, H. K. (2016). Sürdürülebilir turizm yönetiminde örgütlenme. N. Koçak (Editör), Sürdürülebilir turizm yönetimi içinde (s. 148-172). Ankara: Detay Yayınclik.

T. C. Kültür ve Turizm Bakanlığı. (2007). Türkiye turizm stratejisi 2023 eylem planı 2007-2013, Yayın No: 3085, T. C. Kültür ve Turizm Bakanlığı Yayınları, Ankara.

T. C. Kültür ve Turizm Bakanlığı, Ayvalık Turizm Danışma Bürosu Resmi İnternet Sitesi. Genel bilgiler. 02.08.2020 http://www.ayvalikturizmdanismaburosu.ktb.gov.tr/TR-142815/genel-bilgiler.html adresinden erişilmiştir.

Türkay, O. (2014). Destinasyon yönetimi yönetimbilim bakış açısıyla işlevler, yaklaşımlar ve araçlar. Ankara: Detay Yayıncılık.

Uca, S. (2019). Şehir turizmi. Ankara: Detay Yayınclık.

Yıldırım, A. ve Şimşek, H. (2011). Sosyal bilimlerde nitel araştırma yöntemleri. Ankara: Seçkin Yayınclik.

Yılmaz, Ö. D. (2014). Sürdürülebilir turizm ve destinasyon yönetimi. M. Kozak (Editör), Sürdürülebilir turizm kavramlar-uygulamalar içinde (s. 275-291). Ankara: Detay Yayınclik.

Yoon, Y. (2002). Development of a structural model for tourism destination competitiveness fromstakeholders' perspectives. Doctoral Thesis. Virginia: State University, Virginia Polytechnic Institute.

\section{Kaynakça Bilgisi / Citation Information}

Dinç, Y., Kömür, T. ve İlban, M. O. (2021). Sürdürülebilir destinasyon yönetimi için bir model önerisi: Ayvalık örneği. OPUS-Uluslararası Toplum Araştırmaları Dergisi, 17(37), 4376-4399. DOI: 10.26466/opus.896321 